\title{
Homoparentalidade masculina e os sistemas de cuidados parentais
}

\author{
Jéssica Moraes Rosa \\ Luciana Fontes Pessôa
}

\section{RESUMO}

Com o surgimento de novos modelos de configurações familiares, dentre eles as famílias homoparentais, a parentalidade possibilita dar conta das relações instituídas, consequência dos novos arranjos e laços familiares que vão além dos vínculos biológicos e considerando a importância do aspecto social nas funções parentais. Os seres humanos possuem uma predisposição a um conjunto de sistemas parentais independentes e a mecanismos interacionais que formam alianças sociais. Esses sistemas podem ser definidos como conjuntos de comportamentos que podem ser desempenhados por qualquer pessoa, entre eles: cuidado primário, contato corporal, estimulação corporal, estimulação por objeto, contato face a face e envelope narrativo. 0 objetivo da presente pesquisa foi investigar a valorização dos sistemas de cuidado parental em homens cuidadores residentes da cidade do Rio de Janeiro, que estejam em relações homoafetivas e que possuam filhos com idade até 11 anos. A partir de entrevistas semiestruturadas, observou-se uma valorização dos sistemas de cuidados parentais de contato corporal e contato face-a-face, ressaltando a importância do afeto na constituição dessas famílias, descrito, por alguns entrevistados, como essencial para a construção da homoparentalidade. Os achados contribuem, ainda que de maneira preliminar, aos estudos das famílias homoparentais, possibilitando reflexões e discussões à temática.

Palavras-chave: homoparentalidade; parentalidade; sistemas de cuidado parentais.

\section{ABSTRACT}

\section{Gay men parenthood and the parenting system}

With the emergence of new family settings, including homoparental families, the concept of parenthood helps us rethink family beyond biological links, considering the importance of social aspects in parental functions. It is believed that human beings have a predisposition to a set of independent parental systems and to interactional mechanisms that form social alliances. These systems can be defined as behavior sets that can be performed by anyone, namely: primary care, body contact, body stimulation, object stimulation, face-to-face contact and narrative envelope. This paper aimed to investigate the value of parental care systems in male caregivers residing in the city of Rio de Janeiro, Brazil, who are in homoaffective relationships and have children until 11 years old. Based on semi-structured interviews, we observed a valuation of parental care systems of body and face-to-face contacts, emphasizing the importance of affection in the constitution of these families, which, in its turn, was described by some interviewees as essential for the construction of homoparentality. The results contribute, although in a preliminary way, to studies of homoparental families, allowing for reflections and discussions on the theme.

Keywords: homoparentality; parenthood; parenting systems.

Ao estudar a história da família, enfatizando as famílias ocidentais, conclui-se que estas sofreram modificações ou adaptações às mudanças sociais (Poster, 1978; Wagner, Tronco \& Armani, 2011). A família deve ser compreendida como parte de uma elaboração ideológica e social, portanto, não é possível defini-la a partir de características universais, que a reduzem a

\section{Sobre os Autores \\ J. M. R. \\ orcid.org/0000-0001-9241-9703 \\ Pontifícia Universidade Católica do Rio de Janeiro (PUC-RJ) - Rio de Janeiro, RJ \\ jessicamrpsi@gmail.com \\ L. F. P. \\ orcid.org/0000-0002-4446-4283 Pontifícia Universidade Católica do Rio de Janeiro (PUC-RJ) - Rio de Janeiro, RJ \\ pessoalf@gmail.com}

\section{Direitos Autorais}

Este é um artigo de acesso aberto e pode ser reproduzido livremente, distribuído,

transmitido ou modificado, por qualquer pessoa desde que usado sem fins comerciais. 0 trabalho é disponibilizado sob a licença Creative Commons CCBY-NC.

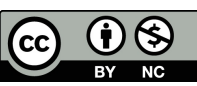




\section{INTERACÃO EM LF PSICOLOGIA}

uma instituição delimitada, desconsiderando o local e o tempo em que se encontra inserida (Dicionário do pensamento social do século XX, 1996). Dessa forma, devemos considerar o termo família não no singular e sim no plural, uma vez que nos encontramos inseridos em uma diversidade social do conceito de família. As novas composições familiares deverão ser entendidas como um reflexo das transformações sociais, ampliando não apenas o conceito de família, mas também suas implicações na sociedade (Wagner, Tronco \& Armani, 2011).

Segundo Dessen (2010), devemos compreender a família a partir dos múltiplos fatores e eventos internos e externos que a influenciam e garantem mudanças em função dos contextos culturais, sociais e históricos nos quais ela se encontra inserida. Portanto, trata-se de um sistema complexo, constituído por construções sociais e reconhecida pelo Estado (Arán, 2011; Bourdieu, 1994; Santos, ScorsoliniComin \& Santos, 2013). Hoje temos como exemplo de novas configurações familiares: as famílias monoparentais, pluriparentais, homoafetivas, reconstruídas ou recasadas, dentre outras (Dessen, 2010; Uziel, 2007).

Diante das inúmeras transformações na forma de ser e pensar a família, e com o surgimento de novos modelos familiares como as famílias homoparentais, o presente estudo objetivou investigar a valorização dos sistemas de cuidado parental em homens que se encontravam em relações homoafetivas e que possuíam filhos com idade até 11 anos, residentes da cidade do Rio de Janeiro.

\section{DA PARENTALIDADE À HOMOPARENTALIDADE}

O termo parentalidade foi inicialmente utilizado em 1961 por Paul-Claude Recamier, psiquiatra e psicanalista francês, a partir de seus trabalhos sobre psicose materna. De acordo com Taperman (2011), o neologismo parentalidade se apresenta como opção de substituição do termo família e, por não discriminar pai e mãe ou função materna e paterna, implica em uma simetria entre as duas figuras. 0 termo se apresenta para dar conta das relações instituídas, consequência dos novos arranjos e laços familiares. Diante da flexibilidade do termo, abre-se espaço para os adultos que estão em posição de ocupar uma função parental.

A parentalidade é, portanto, entendida como produto do parentesco biológico, bem como do tornar-se mãe e pai (Féres-Carneiro \& Magalhães, 2011). Porém, ainda que perpassada por um aspecto biológico evidente, a parentalidade também deve ser compreendida como constituída por um aspecto social. Dessa forma, ela rege, principalmente, as práticas educativas das crianças, exercidas por pessoas, não necessariamente, vinculadas biologicamente a estas. A parentalidade, portanto, diz respeito aos valores e crenças das pessoas que exercem a educação das crianças. Estes, por sua vez, são construídos a partir da história e da cultura (Tudge \& Freitas, 2012).

O termo homoparentalidade foi originado na França, no ano de 1997, pela Associação de Pais e Futuros Pais Gays e Lésbicas (APGL), e deve ser compreendida como o exercício da parentalidade por duas pessoas do mesmo sexo ou, ainda, por uma pessoa que se considera homossexual (Amazonas, Veríssimo \& Lourenço, 2013; Arán, 2011; Cecílio, ScorsoliniComin \& Santos, 2013; Uziel, 2007; Zambrano, 2006).

No ano de 2011, as uniões homoafetivas ganharam espaço nos embates sociais brasileiros, garantindo a conquista de direitos e deveres como o de constituir família. Os ministros do Supremo Tribunal Federal (STF) julgaram a Ação Direta de Inconstitucionalidade (ADI) 4277 e a Arguição de Descumprimento de Preceito Fundamental (ADPF) 132, reconhecendo a união estável entre parceiros do mesmo sexo. Em 2013, o Conselho Nacional de Justiça aprovou uma resolução que obriga os cartórios a celebrarem o casamento civil homoafetivo ou, ainda, converter a união estável entre pessoas do mesmo sexo em casamento. Segundo o Censo do IBGE de 2010 existem 60 mil famílias homoafetivas no cenário brasileiro.

Gato e Fontaine (2014), ao realizarem uma revisão de literatura sobre a homoparentalidade masculina, identificaram que os estudos revistos apresentavam semelhanças entre a hetero e a homoparentalidade. De acordo com Bigner e Jacobsen (1989), os pais gays tendiam a exibir repertórios de qualidades parentais que mesclavam atributos associados, convencionalmente, aos papéis maternos e paternos, por se sentirem pressionados a serem mais competentes. Farr, Forssell e Patterson (2010), ao investigarem famílias que adotaram filhos, não encontraram diferenças no comportamento parental entre casais homoafetivos e casais heterossexuais, ou seja, a orientação sexual não impacta na adaptação dos filhos aos pais.

\section{PRÁTICAS PARENTAIS}

De acordo com Martins, Vieira, Seidl-de-Moura e Macarini (2010), as práticas parentais representam as relações estabelecidas entre os pais e os filhos, sendo permeadas por necessidades distintas que envolvem o cuidado, a educação e o desenvolvimento infantil. Essas relações dependem de alguns fatores como características individuais, presentes nesses sujeitos e em sua prole, orientadas por fatores biológicos, filogeneticamente estabelecidos; além de variáveis ambientais e sociais, resultantes da cultura que moldam o comportamento parental (Manfroi, Macarine \& Vieira, 2011). 


\section{WIINTERACÃO EM ET. PSICOLOGIA}

Keller (2009) afirma que os seres humanos possuem uma predisposição a um conjunto de sistemas parentais independentes e a mecanismos interacionais que formam alianças sociais. Portanto, somos direcionados a estabelecer relações sociais que influenciam, inclusive, no papel parental. Assim, os cuidadores possuem uma predisposição comportamental para cuidar e interagir com os bebês. A parentalidade é composta por sistemas moldados pelas experiências interacionais dos cuidadores e, além disso, a cultura exerce uma forte influência por definir o que é considerado bom ou ruim para a criança (Keller, 2009).

Para Keller (2009), os sistemas parentais são conjuntos de comportamentos que podem ser exercidos por qualquer pessoa. A forma como esses sistemas se moldarão aos cuidadores dependerá de características que dizem respeito aos mecanismos de interação, como: a atenção direcionada ao bebê, sensibilidade aos sinais positivos e negativos emitidos pela criança, calor emocional e velocidade de resposta às queixas da criança (responsividade). Os sistemas, em conjunto com esses mecanismos representam os diferentes contextos de investimento parental como energia, tempo, atenção e as diferentes emoções dirigidas à criança.

Keller (2007) descreve seis sistemas parentais:

a) Cuidado primário representa os primeiros cuidados da infância, como alimentação, abrigo e higiene. Basicamente, sua função consiste em reduzir o desconforto do bebê, garantindo sua sobrevivência e consequente desenvolvimento. Assegura à criança o desenvolvimento da confiança e segurança na proteção e disponibilidade do cuidador (Keller, 2009; Martins, Vieira, Seidl-de-Moura \& Macarini, 2010; Seidl-de-Moura et al., 2014).

b) O Contato corporal consiste em tocar e carregar a criança de forma próxima ao corpo do cuidador, e é responsável pela criação do vínculo entre o cuidador e a criança, descrito por Keller (2009) como um vínculo emocional que permite o desenvolvimento do sentimento de pertencimento da criança. Esse sentimento, associado à aceitação de normas e valores transmitidos intergeracionalmente, prepara esse indivíduo em desenvolvimento para uma vida pautada em harmonia e hierarquia entre os membros da família (Keller, 2009).

c) A Estimulação corporal visa à comunicação corporal, através de atividades específicas para determinada criança. A estimulação se dá por meio do toque e movimentos motores no corpo da criança. Sua função psicológica consiste em intensificar a percepção corporal do bebê, bem como a percepção do ambiente que o cerca, garantindo a promoção de um self corporal próprio (Keller, 2009; Martins, Vieira, Seidlde-Moura \& Macarini, 2010; Seidl-de-Moura et al., 2014). d) Estimulação por objeto possibilita criar uma relação entre o bebê e o mundo dos objetos inanimados que 0 cercam. Através da utilização de brinquedos durante a interação entre cuidador e criança, o bebê é vinculado ao ambiente físico em geral (Keller, 2009; Martins, Vieira, Seidlde-Moura \& Macarini, 2010; Seidl-de-Moura et al., 2014). A função psicológica desse sistema consiste na maturação do sistema cognitivo e o desacoplamento da criança da dependência dos relacionamentos sociais (Keller, 2009).

e) O sistema de contato face-a-face é descrito por Keller (2009) como o mútuo contato visual entre cuidador e criança e o frequente uso da linguagem. Esse sistema demanda um investimento parental, por consistir na exclusiva dedicação de tempo e atenção nessa troca. Também permite à criança pseudo-diálogos, estimulando a percepção de contingências, permitindo à criança se compreender como causadora das ações parentais, possibilitando a sensação de pertencimento e de autoeficácia (Keller, 2009; Seidl-de-Moura et al., 2014).

f) $O$ envelope narrativo consiste na utilização da linguagem pelos cuidadores e, portanto, pode perpassar por todos os outros sistemas parentais, pois em todos eles é possível se comunicar com os filhos através, por exemplo, da fala.

Tendo em vista a escassa literatura na área da homoparentalidade, principalmente no que se refere à masculina (Gato \& Fontaine, 2014), e enfatizando os sistemas parentais, e a importância de pesquisas sobre a temática das famílias homoafetivas, a presente pesquisa teve como objetivo investigar a valorização dos sistemas de cuidado parental em homens cuidadores residentes da cidade do Rio de Janeiro, que estejam em relações homoafetivas e que possuam filhos com idade até 11 anos, portanto ainda sejam crianças, faixa etária estabelecida pelo Estatuto da Criança e do Adolescente (ECA, 1990). A presente pesquisa compôs a dissertação de mestrado da autora principal.

\section{MÉTODO}

\section{PARTICIPANTES}

Participaram da pesquisa 20 pessoas homoafetivas masculinas residentes na cidade do Rio de Janeiro. Estes se encontravam em união estável com parceiros do mesmo sexo e tinham filhos de até 11 anos de idade. Um critério de inclusão adotado é de que fossem homoafetivos desde o início da homoparentalidade. Os participantes foram recrutados através do contatado com grupos de apoios, localizados na cidade do Rio de Janeiro e adjacências. 0 


\section{H NTERAC̄OOEM ET. PSICOLOGIA}

contato deu-se através de ligações, mensagens e e-mails.

Aos participantes que tinham mais de um filho, solicitamos que preenchessem o inventário sociodemográfico com os dados do filho mais novo. Todos os dados sociodemográficos coletados na pesquisa se encontram descritos na Tabela 1.

Os participantes foram divididos em três grupos associados à forma como se deram as parentalidades, são eles: adoção afetiva $(N=2)$, adoção legal $(N=14)$ e tecnologias reprodutivas $(\mathrm{N}=4)$. 0 termo adoção afetiva foi criado pelos próprios participantes para explicar a forma de parentalidade que não possui implicações legais, ou seja, a criança não se encontrava registrada no nome do casal, entretanto era criada por eles. Na adoção legal os filhos estavam registrados no nome dos pais adotantes, e abrangeu a maior quantidade de participantes dessa pesquisa.

Tabela 1. Caracteristicas sociodemográficas dos participantes da pesquisa

\begin{tabular}{|c|c|c|c|}
\hline & Adoção & Adoção & Tecnologias \\
\hline & Afetiva & Legal & Reprodutivas \\
\hline Idade do pai $\boldsymbol{M}(D P)$ & $46,5 \pm 3,5$ & $41,8 \pm 6,24$ & $41,7 \pm 12,9$ \\
\hline Idade da criança (anos) $\boldsymbol{M}$ (DP) & $11 \pm 0$ & $4,54 \pm 3,02$ & 1,0 \\
\hline \multicolumn{4}{|l|}{ Escolaridade $n(\%)$} \\
\hline Médio Completo & - & $1(7,1 \%)$ & $2(50 \%)$ \\
\hline Superior Completo & - & $6(42,9 \%)$ & $1(25 \%)$ \\
\hline Pós Graduação & $2(100 \%)$ & $7(50 \%)$ & $1(25 \%)$ \\
\hline \multicolumn{4}{|l|}{ Renda $n(\%)$} \\
\hline Até $R \$ 10.000$ & $2(100 \%)$ & $8(61,5 \%)$ & $2(50 \%)$ \\
\hline De $R \$ 10.001$ até 15.000 & - & $4(30,98 \%)$ & - \\
\hline Acima de 15.001 & - & $1(7,7 \%)$ & $2(50 \%)$ \\
\hline \multicolumn{4}{|l|}{ Estado Civil $\boldsymbol{n}(\%)$} \\
\hline Casado & $2(100 \%)$ & $8(57,1 \%)$ & $2(50 \%)$ \\
\hline União Estável & - & $6(42,9 \%)$ & $2(50 \%)$ \\
\hline \multicolumn{4}{|l|}{ Sexo Criança $n(\%)$} \\
\hline Masculino & - & $5(71,4 \%)$ & $1(100 \%)$ \\
\hline Feminino & $1(100 \%)$ & $2(28,6 \%)$ & - \\
\hline
\end{tabular}

Já o termo tecnologias reprodutivas abrange um conjunto de conhecimentos e procedimentos médicos paliativos que objetiva a fecundação, quando diante de condições de in/ hipofertilidade humana (Pontes, Feres-Carneiro \& Magalhães, 2015). Os quatro entrevistados que fazem parte desse grupo realizaram a técnica de 'barriga de aluguel', que consiste na fertilização in vitro (FIV) de um embrião, fecundado com o sêmen dos pais em um óvulo de uma doadora anônima, e transferido para o útero de uma mulher, consistindo na doação temporária desse útero para a gestação do bebê. Cabe ressaltar que essa técnica não é permitida no Brasil; os casais a realizaram nos Estados Unidos.

\section{INSTRUMENTO}

\section{Formulário de dados sociodemográficos}

Composto por informações referentes à idade do pai e da criança, nível de escolaridade e renda do pai, sexo da criança e como se deu a parentalidade.

\section{Entrevista semiestruturada}

Foram apresentadas aos entrevistados, individualmente, cinco imagens que representavam, cada uma, um dos cinco sistemas parentais de Keller (2012): cuidados básicos, estimulação corporal, contato corporal, estimulação por objeto e contato face-a-face. O sexto sistema, envelope narrativo, não foi incluído na pesquisa por não ser possível representá-lo visualmente. Em seguida, foi solicitado aos participantes que ordenassem as imagens por ordem de importância, da mais importante para a menos importante.

Essas imagens, a princípio, fizeram parte de um estudo desenvolvido por Seild-de-Moura et al., (2014), que objetivou investigar a valorização dos sistemas de cuidado em um grupo com diferentes cuidadores de crianças com até um ano de idade (mães, avós, babás e educadoras de creches). As fotografias foram submetidas a jurados que avaliaram se elas condiziam aos sistemas, como proposto.

Cada fotografia utilizada apresentava a imagem de uma mãe com um bebê, em um ambiente que representava sua casa, ilustrando cada um dos sistemas: cuidados básicos (mãe banhando a criança), contato corporal (mãe segurando o bebê próximo a seu corpo), face a face (mãe e o bebê, que se encontra em seu colo, estabelecendo contato visual), estimulação corporal (criança deitada e a mãe massageando seus pés), e estimulação por objeto (mãe mostrando um brinquedo para a criança, enquanto ela se encontra deitada).

Durante a realização dessa atividade se utilizou o gravador. 


\section{W INERACÄOEM ET PSICOLOGIA}

\section{PROCEDIMENTOS}

\section{Dados da coleta}

Inicialmente foi apresentado o termo de consentimento livre e esclarecido. Após explicação do termo foi solicitada sua assinatura. Todos os participantes foram entrevistados individualmente em suas próprias casas, como solicitado por eles.

Após responderem 0 formulário de dados sociodemográfico, foi pedido aos entrevistados que organizassem as imagens por ordem de importância: da mais importante para a menos importante. Em seguida, foi solicitado que eles explicassem a escolha da ordem e comentassem sua percepção sobre cada imagem. Toda a coleta teve duração média de 20 minutos.

\section{Análise dos dados}

Quanto à entrevista semiestruturada, foi solicitado à cada participante que atribuísse uma ordem de importância a cada imagem que representa um dos cinco sistemas de cuidado parental, da mais importante a menos importante, e sua escolha foi associada a um score. Dessa forma, a imagem escolhida que correspondia a mais importante recebia o maior score que equivalia a cinco pontos, a segunda imagem na ordem de importância recebia quatro pontos e, assim, sucessivamente, até a última imagem, que representa a menor importância, recebendo um ponto. Assim, cada imagem era pontuada a partir da ordem de importância escolhida, tratando-se de um dado ordinal. Para a comparação dos valores atribuídos a cada sistema de cuidado parental utilizamos o teste $t$ pareado.

As falas dos participantes foram audiogravadas; posteriormente, as entrevistas foram transcritas na íntegra e o material resultante constituiu o corpus de análise. Para interpretar os dados e explicitar as percepções dos participantes acerca da assunção ao papel parental, utilizouse a técnica de análise de conteúdo na modalidade temática (Bardin, 1977). Foram percorridas as três etapas operacionais pertinentes à análise temática: pré-análise, exploração do material e tratamento/interpretação dos resultados obtidos. Realizou-se uma leitura flutuante do corpus. A seguir, os dados foram agrupados segundo as unidades de registro que emergiram do material empírico, tendo como eixo condutor o objetivo do estudo. A partir dessa etapa, foram selecionados trechos do material considerados relevantes à constituição das unidades de significação, dando origem aos temas. Estes foram codificados e organizados, conforme a similaridade de conteúdos, em categorias temáticas.

Categorizou-se a fala dos participantes entre: os sistemas de cuidados parentais, que inclui os cinco sistemas; e a construção da parentalidade, que buscou abranger como se deu esse processo.

\section{Cuidados Éticos}

A pesquisa seguiu as normas da Comissão Nacional de Ética em Pesquisa (CONEP, Conselho Nacional de Saúde, Ministério da Saúde, Brasil) e do Código de ética Profissional dos Psicólogos, atendendo às exigências estabelecidas pela Resolução 510/16 do Conselho Nacional de Saúde. Foi submetido e aprovado pela comissão de ética em pesquisa da Pontifícia Universidade Católica do Rio de Janeiro ( $n^{\circ}$ 2016-13).

\section{RESULTADOS E DISCUSSÃO}

Por buscar analisar a valorização dos sistemas parentais para esses homens que se encontram em posição de cuidadores, realizou-se um teste $t$ pareado para a comparação dos valores atribuídos aos cinco sistemas de cuidado parental. Os resultados indicaram que os participantes valorizam mais o sistema contato corporal do que os sistemas estimulação corporal $(t(19)=5,47 ; p<0,001)$, cuidados básicos $(t(19)=2,82 ; p=0,011)$ e estimulação por objetos $(t(19)=8,01 ; p<0,001)$. 0 sistema face-a-face, por sua vez, foi mais valorizado do que os sistemas de estimulação corporal $(t(19)=4,17 ; p=0,001)$ e estimulação por objetos $(t(19)=5,30 ; p<0,001)$. O sistema de cuidados básicos, por fim, foi mais valorizado do que o sistema estimulação por objetos $(t(19)=3,91 ; p=0,001)$. A Figura 1 apresenta as médias de valorização dos cinco sistemas de cuidado parental.

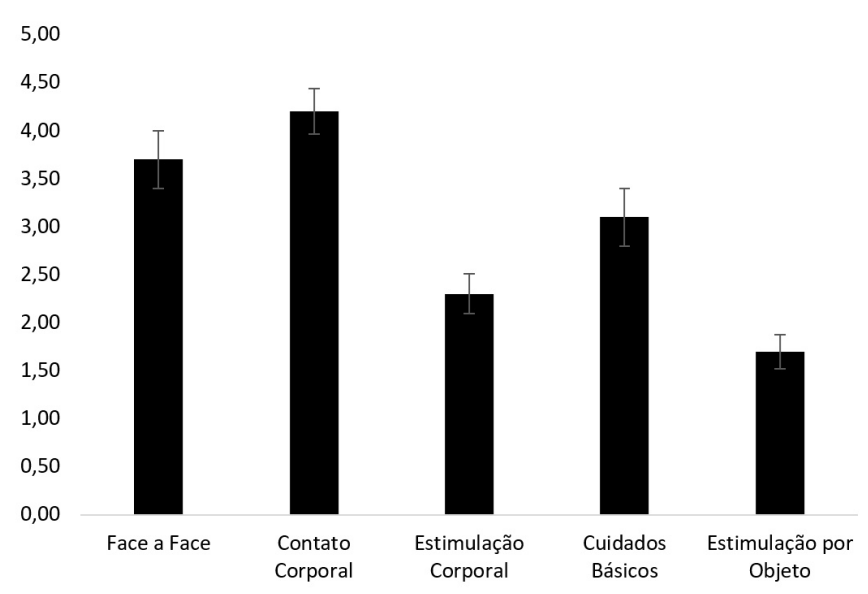

Figura 1. Média de valorização dos cinco sistemas de cuidado parental. 


\section{MI* INTERACÃO EM LF PSICOLOGIA}

Os dados, portanto, apontam que os sistemas de cuidado mais valorizados pelos participantes em geral são o contato corporal e o contato face-a-face, indicando uma preferência desses homens por vivenciarem com seus filhos momentos de afeto e proximidade. Esse mesmo resultado foi observado na pesquisa realizada por Seidl-de-Moura et al. (2014) com mães, avós, babás e educadoras infantis no estado do Rio de Janeiro. Em contraponto, a pesquisa realizada por Martins, Vieira, Seidl-de-Moura e Macarini (2010), com 606 mães residentes de capitais e cidades pequenas do Brasil, apontou que as práticas de cuidados primárias, descritas pelos autores como os sistemas de cuidados básicos e contato corporal, são mais valorizadas por essas mães do que as práticas de estimulação, que engloba os sistemas de estimulação corporal, estimulação por objeto e contato facea-face.

No contexto urbano é estimulada a autoexpressão e competição, sendo encorajado o direito de expressar suas opiniões e negociar seus pontos de vista, de forma a otimizar seus interesses e desejos (Keller, 2012). Dessa forma, essas famílias adotam estratégias de socialização que enfatizam a autonomia e o tempo dedicado ao filho. Portanto, há a valorização do contato face-a-face entre cuidador e criança. Já em contextos que valorizam o desenvolvimento da interdependência e relação, o contato corporal é mais frequentemente valorizado (Keller, 2012; Seidl-de-Moura et al., 2014). Cabe ressaltar que os estudos citados foram realizados com mulheres, não levando em consideração, por exemplo, o modelo familiar em que se encontravam inseridas. Talvez por isso, em comparação ao segundo estudo citado, o resultado tenha se apresentado diferente.

De acordo com Gato e Fontaine (2014), a motivação à parentalidade por esses homens homoafetivos pode estar associada a um processo de negociação com diversas instâncias familiares e sociais, que se relacionam com circunstâncias de vida particulares. Bigner e Jacobsen (1989) ao realizarem um estudo comparando pais homoafetivos e pais heterossexuais, concluíram que os homoafetivos tendiam a se preocupar mais em atender às necessidades dos filhos a serem consistentes com os limites e regras estabelecidos às crianças, por se sentirem pressionados a serem mais competentes, tendendo a mesclar atributos associados aos papéis maternos e paternos.

Os homens participantes valorizavam os sistemas de cuidados que mais apresentavam comportamentos representantes do afeto, como o abraçar e olhar no olho mantendo a face próxima a da criança, pois, em suas falas, explicitaram a importância do afeto na constituição das relações com seus filhos. Para eles, a parentalidade e, portanto, suas famílias eram construídas através dos vínculos afetivos presentes nessas relações, como observado na fala desse entrevistado:

"Eu tenho um filho adotado, pra mim a parentalidade começa no afeto, começa no desejo de ter alguém, não começa no acaso ou na sexualidade ou na instituição do casamento, começa na vontade" (participante 1, 46 anos).

Os sistemas menos valorizados pelos participantes dessa pesquisa foram estimulação corporal, seguida pela estimulação por objeto, resultado também observado na pesquisa de Seidl-de-Moura et al. (2014).

\section{CONTATO CORPORAL}

Esse sistema foi descrito pelos participantes da pesquisa como suporte emocional para a criança, através do cuidado, afeto, acolhimento e carinho, por meio do contato com a pele da mãe.

"O primeiro é o afeto [...] eu acho que o afeto é o principal, a relação afetiva, você desenvolver a relação de contato primordial com a criança, pra mim é o principal" (participante 2, 36 anos).

Um dos entrevistados aponta, também, que a descrição do sistema de contato corporal se trata de um comportamento típico de cuidadores:

"Isso daqui, esse jeito que ela tá segurando, é um jeito muito simbólico que só pai e mãe seguram, né? Apesar de várias pessoas pegarem no colo, tá passando essa coisa de peito com peito, sabe? Assim, do acolhimento, não só uma pessoa segurando uma criança no colo pra não tá no chão, mas uma coisa de acolhimento, de: 'tô te passando segurança, você tá comigo, eu tô aqui pra te proteger', essa coisa toda" (participante 5, 35 anos)

A imagem também foi descrita como uma troca de afetos que favorecem tanto o cuidador como a criança:

“É interessante porque é a única das fotos em que a figura parental não tá apenas como cuidadora, ela tá também em êxtase, ela tá também de olhos fechados, ela também tá vivendo um grande amor. [...] Não tem um cuidador e um cuidado, não tem, claro que tem, mas não é o que transparece nessa imagem. Não tem um desenvolvido e um em desenvolvimento, o forte e o frágil, aqui tem dois quase num nível igual de fragilidade, de entrega, é onde essa relação é mais horizontal, no afeto" (participante 1, 46 anos).

Dada a importância do afeto, como observado a partir da fala dos entrevistados, para a constituição da parentalidade, e por representar esse sentimento de acolhimento e 


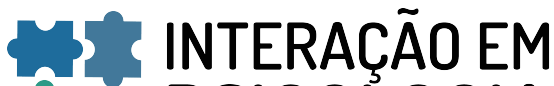 ET PSICOLOGIA}

pertencimento, o sistema contato corporal foi o mais valorizado pelos participantes.

\section{CONTATO FACE-A-FACE}

Os entrevistados, em sua maioria, descreveram a imagem que representa esse sistema como um contato essencial, que representa vínculo e troca de afetividades, permitindo à criança sentir-se amada, ressaltando a importância da troca de olhares.

"Eu acho que aqui ela tá olhando diretamente no olho do filho, né? Eu acho que é primordial você passar um amor diretamente do pai pro filho. Essa é, eu acho, a base de tudo, entendeu? A reciprocidade do olhar do filho pra ela, eu acho que é a base de tudo, sem isso qualquer outra função aqui uma babá poderia tá fazendo, mas esse contato aqui eu acho que é primordial do pai com o filho" (participante 6, 36 anos).

Martins, Vieira, Seidl-de-Moura e Macarini, (2010) apontam que essa troca visual, característica do contato face a face, é altamente estimulante e repleta de afeto, constituindo-se de curtos eventos interacionais carregados de informações cognitiva e social, expondo a criança a estes.

"[...] essa foto tá, assim, ela olhando pra ele é como se ela estivesse ensinando, falando alguma coisa pra ele dizendo: 'olha filho é assim...'. Transmitindo, que faz parte desse conjunto, desse pacote de cuidados que a gente tem, que é essa transmissão de informações do que é certo e o que é errado" (participante 7, 37 anos).

\section{CUIDADO PRIMÁRIO OU CUIDADOS BÁSICOS}

Os entrevistados reconheceram a importância desse cuidado para garantir a sobrevivência e bem-estar da criança:

"Bem, a princípio, aqui pra mim, a questão do cuidado, a primeira coisa que eu vejo como uma, não diria uma obrigação, mas um papel [...] inicialmente com a sobrevivência, com o bem-estar na verdade. Cuidado tem a ver com o bem-estar físico, os cuidados de um ser que ainda não pode se cuidar sozinho" (participante 9, 44 anos).

Apesar de reconhecerem a importância dos cuidados básicos, esse sistema não foi 0 mais valorizado, possivelmente porque os entrevistados consideraram que esse tipo de cuidado pode ser realizado por qualquer indivíduo, não necessariamente os pais:

"apesar de ser uma necessidade básica, eu acho que é meio aquilo que qualquer um pode fazer" (participante 10, 53 anos).
Alguns entrevistados ressaltaram a importância desse sistema para a transmissão de confiança e segurança:

"O P. (nome da criança) dá muita importância pra isso, pro cuidado, ele fala: 'pai, obrigado por cuidar de mim, vocês tão cuidando de mim'. Acho que o cuidado pra ele que veio, uma criança que passou a idade de pequeno até os cinco anos no abrigo, ele sente essa coisa do cuidado como uma coisa muito importante" (participante 5, 35 anos).

\section{ESTIMULAÇÃO CORPORAL}

Alguns dos participantes associaram a imagem que representava esse sistema à estimulação do desenvolvimento motor: "eu acho que é o papel de estimular, de possibilitar que ele se desenvolva, ter independência" (participante 10, 53 anos).

"Essa imagem me pareceu uma coisa que não é só de brincadeira, tem uma coisa de estímulo também, essa coisa de pegar o bebê e fazer os pequenos exercícios, e sensorial e tudo mais [...] esse estímulo mesmo, essa coisa meio fisioterapia que você tem que fazer" (participante 5, 35 anos).

Outros descreveram a imagem como parte dos cuidados básicos: "você faz um tipo de exercício com as pernas da criança quando ela tá com cólica, pra expelir gases. Então pra mim isso é um outro tipo de cuidado" (participante 13, 39 anos).

"Aqui é o cuidado, eu pensei assim no cuidado com ele, trocar fralda, ter esse cuidado de tá tendo contato com ele nessa troca de fralda" (participante 14, 46 anos).

Um terceiro grupo de participantes descreveu a imagem como brincadeira:

"Essa daqui eu acho que ela tá brincando" (participante 15,37 anos)

"Esse quarto é interação, né? O lúdico, um momento de descontração dos dois" (participante 7, 37 anos).

\section{ESTIMULAÇÃO POR OBJETO}

Todos os entrevistados descreveram a imagem que representa esse sistema como um momento de brincadeira entre a mãe e o filho:

"[...] tem que ter essa coisa de você satisfazer também o desejo da criança, não só ficar cuidando, cuidando, cuidando, a criança também precisa de uma interação, de uma brincadeira, de uma coisa que satisfaça o emocional 


\section{W'INTERACÃO EM ET PSICOLOGIA}

dele, de tá interagindo com o pai de forma mais lúdica" (participante 6, 36 anos).

Outros reconheceram a função desse sistema para a exploração do ambiente pela criança e desenvolvimento cognitivo da mesma:

"Mais da questão da interação, de desenvolvimento cultural até, de brincar e de ter conhecimentos, informações" (participante 10, 53 anos).

"A gente vai lá pra hora da brincadeira, que eu também acho igualmente importante, eu acho que a gente estimula várias coisas, raciocínio, a criatividade da criança" (participante 11, 34 anos).

\section{CONSIDERAÇÕES FINAIS}

Evidencia-se que as novas configurações familiares vêm conquistando espaço na sociedade, tanto no tocante à política, com o reconhecimento dos seus direitos e deveres, quanto nos estudos das ciências sociais e humanas, seja na psicologia, na antropologia ou no direito. Entretanto, os estudos referentes aos sistemas parentais e esse modelo familiar são escassos (Gato \& Fontaine, 2014).

Assim, deve-se levar em consideração as inúmeras variáveis que influenciam os distintos arranjos familiares, sendo fundamental considerar as demandas afetivas dos indivíduos presentes nesses novos tipos de família. Com isso, a conjugalidade, parentalidade e filiação devem ser compreendidas baseadas nos laços de afeto.

A parentalidade, portanto, diz respeito aos valores e crenças das pessoas que exercem a educação destas. Dessa forma, está ligada ao fazer, implicando tudo que perpassa ao cotidiano durante as práticas educativas, que sofrem influência, em parte, de valores e crenças daqueles que exercem a parentalidade (Tudge \& Freitas, 2012) e que influenciam na valorização de alguns sistemas parentais em detrimento de outros.

A presente pesquisa, ao investigar os sistemas parentais desses homens cuidadores que se encontram em relações homoafetivas e residem na cidade do Rio de Janeiro apresentou como resultado uma maior valorização do sistema contato corporal, seguido, na seguinte ordem, pelo contato face-a-face, cuidados básicos, estimulação corporal e, como menos valorizado, estimulação por objeto.

Compreende-se que os sistemas contato corporal e contato face-a-face foram os mais valorizados por representarem, segundos os entrevistados, relação de vínculo e afeto entre cuidador e criança, sendo, para eles, fundamental para a construção da parentalidade, ressaltando a importância do afeto na constituição dessas famílias.

Resultado similar foi encontrado por Seidl-de-Moura et al. (2014) ao realizar um estudo com mães, babás e educadoras infantis no estado do Rio de Janeiro. Assim, estes dados obtidos apontam que a valorização desses sistemas pode ser resultado da influência cultural presente nesse estado brasileiro, e que, talvez, em função dos achados desse estudo, com a especificidade da sua amostra, independa da configuração parental. De toda forma se faz necessário a realização de outras pesquisas que apresentem maior número de entrevistados, bem como uma ampliação no território investigado, expandindo-se a outros cenários brasileiros.

Pode-se informar que, diante dos resultados obtidos, o presente estudo atingiu os objetivos propostos, entretanto, cabe ressaltar suas limitações. Com um maior número de participante e, assim, de entrevistados, teríamos mais dados para compor os resultados. Porém, a dificuldade em localizar participantes que se encaixavam na descrição necessária, associado ao curto tempo destinado à pesquisa no mestrado impossibilitou um maior número.

Outras limitações dos estudos se referem à metodologia utilizada, caso fosse a observação direta, resultados diferentes poderiam surgir, já que no estudo atual foi utilizado um inventário e realizada uma entrevista semiestruturada, também por buscar otimizar os dados diante de um curto tempo destinado à pesquisa. As imagens utilizadas para compor a pesquisa apresentavam mães se relacionando com seus filhos, assim, sugere-se a utilização de imagens com homens cuidadores nos próximos estudos. No entanto, os dados obtidos neste estudo fornecem indícios que podem ser investigados posteriormente utilizando outros instrumentos metodológicos. Além disso, sugere-se que estudos futuros sejam realizados com participantes de diferentes faixas etárias, assim como com seus filhos.

Assim, os achados contribuem, ainda que de maneira preliminar, aos estudos das famílias homoafetivas, enfatizando os sistemas parentais, possibilitando reflexões e discussões à temática da homoparentalidade masculina.

\section{DECLARAÇÃO DE FINANCIAMENTO}

A pesquisa foi financiada, parcialmente, pela bolsa de mestrado da primeira autora (CAPES).

\section{DECLARAÇÃO DA CONTRIBUIÇÃO DOS AUTORES}

J. M. R. foi responsável pela investigação, redação inicial, tabulação de dados; L. F. P. contribuiu com a supervisão; J. M. 


\section{H NTERAC̄̈OEM PSICOLOGIA}

R. e L. F. P. são as responsáveis pela revisão final.

\section{DECLARAÇÃO DE CONFLITOS DE INTERESSE}

Os autores declaram que não há conflitos de interesse nesse artigo.

\section{REFERÊNCIAS}

Amazonas, M. C. L. A., Veríssimo, H. V. \& Lourenço, G. O. (2013). Adoção de crianças por gays. Psicologia \& Sociedade, 25(3), 631-641. doi: 10.1590/S010271822013000300017

Arán, M. (2011). Políticas do desejo na atualidade: psicanálise e a homoparentalidade. Revista Psicologia Política, 11(21), 59-72. doi: 10.1590/S0104026X200900300002

Bardin, L. (1977). Análise de conteúdo. Lisboa, PLx: Edições 70.

Bigner, J. \& Jacobsen, R. B. (1989). Parenting behaviors of homosexual and heterosexual fathers. In F.W. Bozett (Ed.), Homosexuality and the family (pp. 173-186). New York, NY: Harrington Park.

Bourdieu, P. (1999). A dominação masculina (M. H. Kuhner, Trad.). Rio de Janeiro, RJ: Bertrand Brasil.

Brasil. (1988). Constituição da República Federativa do Brasil de 1988 .

Cecílio, M. S., Scorsolini-Comin, F., \& Santos, M. A. (2013). Produção científica sobre adoção por casais homossexuais no contexto brasileiro. Estudos de Psicologia, 18(3), 507-516. doi: 10.1590/S1413294X2013000300011

Dessen, M. A. (2010). Estudando a família em desenvolvimento: desafios conceituais e teóricos. Psicologia: Ciência e Profissão, 30, 202-219. doi: 10.1590/ S1414-98932010000500010

Dicionário do pensamento social do século XX. (1996). Rio de Janeiro, RJ: Jorge Zahar.

Farr, R. H., Forssell, S. L., \& Patterson, C. J. (2010). Parenting and child development in adoptive families: Does the parental sexual orientation matter? Applied Developmental Science, 14(3), 164-178.

Féres-Carneiro, T., \& Magalhães, A. S. A. (2011). Parentalidade nas múltiplas configurações familiares contemporâneas. In: Moreira, L.V.C. \& Rabinovich, E. P. Família e parentalidade: olhares da psicologia e da história (pp. 117 - 133). Curitiba, PR: Juruá.

Gato, J., \& Fontaine, A. M. (2014). Homoparentalidade no masculino: uma revisão de literatura. Psicologia e Sociedade, 26(2), 312-322.
IBGE. Censo demográfico. 2010. Recuperado de www.censo2010.ibge.gov.br

Keller, H. (2007). Cultures of infancy. Mahwah, NJ: Erlbaum.

Keller, H. (2009). Development as the interface between biology and culture: a conceptualisation of early ontogenetic experiences. In: Keller, H., Poortinga, Y. H., \& Schoelmerich, A. (Eds.). Between Culture and Biology (pp. 1-32). Cambridge, UK: Cambridge University Press, in press.

Keller, H. (2012). Autonomy and relatedness revisited: cultural manifestations of universal human needs. Child Development Perspectives, 6(1), 12-18.

Manfroi, E. C., Macarini, S. M., \& Vieira, M. L. (2011). Comportamento parental e o papel do pai no desenvolvimento infantil. Revista brasileira: crescimento e desenvolvimento humano, 21(1), 59-69. doi: 10.1590/ S0104-12822011000100007

Martins, G. D. F., Vieira, M. L., Seidl-de-Moura, M. L., \& Macarini, S. M. (2010). Crenças e práticas de cuidado entre mães residentes em capitais e pequenas cidades brasileiras. Psicologia: reflexão e crítica, 24(4), 692-701. doi: 10.1590/S0102-79722011000400009

Pontes, M. F., Feres-Carneiro, T., \& Magalhães, A. (2015). Famílias homoparentais e maternidade biológica. Psicologia e Sociedade, 27(1), 189-198. doi: 10.1590/1807-03102015

Poster, M. (1979). Teoria crítica da família (A. Cabral,Trad.). Rio de Janeiro, RJ: Zahar.

Santos, Y. G. S., Scorsolini-Comin, F., \& Santos, M. A. (2013). Homoparentalidade masculina: revisando a produção científica. Psicologia: Reflexão e Crítica, 26(3), 572-582. doi: 10.1590/S0102-79722013000300017

Seidl-de-Moura, M. L. et al. (2014). Beliefs of mothers, nannies, grandmothers and daycare providers concerning childcare. Paidéia, 24(59), 341-349. doi: 10.1590/198243272354201302

Taperman, D. (2011). Família, parentalidade e época: articulações possíveis. In: Moreira, L.V.C.; Rabinovich, E. P. Familia e parentalidade: olhares da psicologia e da história (pp. 157-167). Curitiba, PR: Juruá.

Tudge, J. R. H., \& Freitas, L. B. L. (2012). Parentalidade: uma abordagem ecológico-cultural. In: Piccinini, C. A.; Alvarenga, P. (Orgs). Maternidade e paternidade: a parentalidade em diferentes contextos (pp. 171-196). São Paulo, SP: Casa do Psicólogo.

Uziel, A. P. (2007). Homossexualidade e Adoção. Rio de Janeiro, RJ: Garamonde.

Wagner, A., Tronco, C., \& Armani, A. B. (2011). Os desafios da família contemporânea: revisitando conceitos. In: Wagner, A. e cols (Orgs). Desafios Psicossociais da Família Contemporânea: pesquisas e reflexões (pp. 19-35). Porto Alegre, RS: Artmed. 


\section{H'INTERACÃO EM \\ ET PSICOLOGIA}

Jéssica Moraes Rosa e Luciana Fontes Pessôa

Zambrano, E. (2006). Parentalidades "impensáveis": pais/ mães homossexuais, travestis e transexuais. Horizonte Antropológico, 12(26), 123-147. doi: 10.1590/S1413-

Primeira decisão editorial: 17/05/2018

294X2013000300011

Aceite em 13/09/2018 